\title{
Staphylococcus aureus CidC Is a Pyruvate:Menaquinone Oxidoreductase
}

\author{
Xinyan Zhang, Kenneth W. Bayles, ${ }^{\dagger}{ }^{\dagger}{ }^{\ddagger}$ and Sorin Luca ${ }^{\dagger}$ \\ ${ }^{\dagger}$ Department of Pharmaceutical Sciences and ${ }^{\ddagger}$ Department of Pathology \& Microbiology, University of Nebraska Medical Center, \\ Omaha, Nebraska 68198-5900, United States
}

\section{Supporting Information}

ABSTRACT: Recent studies have revealed an important role for the Staphylococcus aureus CidC enzyme in cell death during the stationary phase and in biofilm development and have contributed to our understanding of the metabolic processes that are important in the induction of bacterial programmed cell death (PCD). To gain more insight into the characteristics of this enzyme, we performed an in-depth biochemical and biophysical analysis of its catalytic properties. In vitro experiments show that this flavoprotein catalyzes the oxidative decarboxylation of pyruvate to acetate and carbon dioxide. CidC efficiently reduces menadione, but not CoenzymeQ $Q_{0}$, suggesting a specific role in the $S$. aureus respiratory chain. CidC exists as a monomer under neutral-pH conditions but tends to aggregate and bind to artificial lipid membranes at acidic $\mathrm{pH}$, resulting in enhanced enzymatic activity. Unlike its Escherichia coli counterpart,

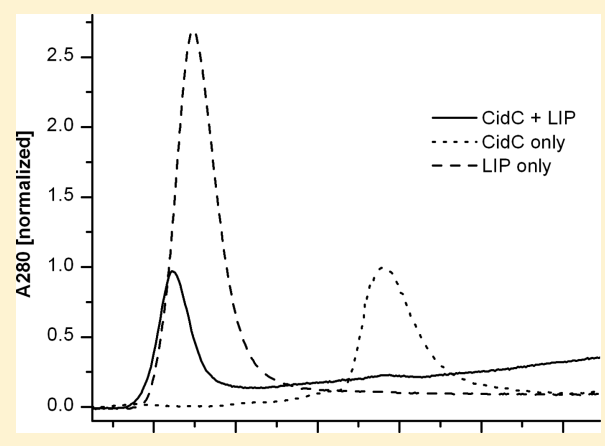
PoxB, CidC does not appear to be activated by other amphiphiles like Triton X-100 or octyl $\beta$-D-glucopyranoside. In addition, only reduced $\mathrm{CidC}$ is protected from proteolytic cleavage by chymotrypsin, and unlike its homologues in other bacteria, protease treatment does not increase CidC enzymatic activity. Finally, CidC exhibits maximal activity at $\mathrm{pH} 5.5-5.8$ and negligible activity at $\mathrm{pH}$ 7-8. The results of this study are consistent with a model in which CidC functions as a pyruvate:menaquinone oxidoreductase whose activity is induced at the cellular membrane during cytoplasmic acidification, a process previously shown to be important for the induction of bacterial PCD.

S tudies of the Staphylococcus aureus cidABC and $\operatorname{lrg} A B$ operons have revealed a complex network of membraneassociated proteins and metabolic enzymes with a significant role in the regulation of bacterial viability. ${ }^{1-3}$ The integral membrane proteins CidA and LrgA have been suggested to functionally resemble members of the Bcl-2 family of proteins that control apoptosis in eukaryotic organisms, ${ }^{4}$ and mutations in cidA and $\operatorname{lrg} A$ are associated with cell death phenotypes. ${ }^{5,6}$ It has been therefore proposed that the widely conserved cid and $\operatorname{lrg}$ operons control bacterial $\mathrm{PCD},{ }^{7,8}$ which most dramatically manifests within the multicellular environment of the biofilm. ${ }^{6,9}$

The Cid/Lrg system has been shown to rely on the activities of two membrane proteins that function in a manner that is analogous to bacteriophage-encoded holins, known to be required for the control of cell death and lysis during the lytic cycle of a bacteriophage infection. ${ }^{10}$ Similar to holins, the CidA and $\operatorname{LrgA}$ proteins are small, integral membrane proteins that form high-molecular weight oligomers. ${ }^{11}$ In addition, recent studies indicate that the gene products of the cid $A B C$ and $\operatorname{lrg} A B$ operons have opposing functions in the control of cell death and lysis. ${ }^{3,12}$ These striking functional and biochemical properties of the Cid and Lrg proteins have laid the foundation for the model that they represent the progenitors of the regulatory control of apoptosis in more complex eukaryotic organisms. ${ }^{13,14}$

Our laboratory has recently demonstrated that cidC, which is the third gene of the cidABC operon and was reported to encode a pyruvate oxidase family protein, ${ }^{15}$ also plays a major role in the control of bacterial PCD by potentiating cell death. ${ }^{16}$ This process was shown to involve the CidC-mediated conversion of intracellular pyruvate to acetate, which leads to cytoplasmic acidification and respiratory inhibition. Pyruvate is an important intermediate in carbohydrate metabolism that is directly metabolized by many types of flavoenzymes in bacteria. $^{17-21}$ Two classes of thiamin diphosphate (TPP)dependent and flavin-dependent enzymes are differentiated by the Enzyme Commission (EC) according to their immediate electron acceptor: pyruvate oxidases or pyruvate: $\mathrm{O}_{2}$-oxidoreductases (EC 1.2.3.3) pass the electron directly to oxygen, while pyruvate:quinone oxidoreductases (EC 1.2.5.1) pass the electron to a quinone. The former enzyme requires phosphate and produces acetyl phosphate, while the latter requires water and generates acetate with the full reactions shown in eq I.

$$
\begin{gathered}
\text { pyruvate }+ \text { phosphate }+\mathrm{O}_{2} \\
\rightarrow \text { acetyl-phosphate }+\mathrm{CO}_{2}+\mathrm{H}_{2} \mathrm{O}_{2} \\
\text { pyruvate }+\mathrm{H}_{2} \mathrm{O}+\text { quinone } \rightarrow \text { acetate }+\mathrm{CO}_{2}+\text { quinol }
\end{gathered}
$$

Received: June 16, 2017

Revised: August 13, 2017

Published: August 15, 2017 
Well-characterized examples of these enzymes include pyruvate:oxygen 2-oxidoreductases like Lactobacillus plantarum POX and Streptococcus pneumoniae SpxB, which consume oxygen and participate in cellular signaling via the generation of acetyl phosphate ${ }^{22}$ and in cell death via the production of $\mathrm{H}_{2} \mathrm{O}_{2}{ }^{23,24}$ Pyruvate:quinone oxidoreductases like Escherichia coli PoxB and Corynebacterium glutamicum PQO, on the other hand, directly transfer electrons from the cytoplasm into the membrane respiratory chain. The enzymatic properties and structures have been determined for both PoxB and PQO, and the results demonstrate that the activities of these enzymes are largely subject to substrate concentration and membrane binding status. ${ }^{25,26} \mathrm{~S}$. aureus $\mathrm{CidC}$ shares about $33 \%$ amino acid sequence identity with both $\mathrm{PQO}$ and $\mathrm{PoxB}$, and previous in vivo studies suggest that $\mathrm{CidC}$ is responsible for the conversion of pyruvate to acetate. ${ }^{15,16,27}$ The study presented here focuses on elucidating the basic biochemical and biophysical properties of CidC and suggests its activity as a pyruvate:quinone oxidoreductase, which uses menaquinone as a direct electron acceptor. In addition, these studies demonstrate that CidC has unique substrate, cofactor, and membrane binding properties, which are different from those of previously characterized homologous enzymes. The findings shed light on how this enzyme plays a critical role during cytoplasmic acidification and how this is important for bacterial PCD.

\section{EXPERIMENTAL PROCEDURES}

Materials. For protein purification, chromatographic columns and an AKTA Purifier 10 from GE Healthcare (Pittsburgh, PA) as well as rotors and an Allegra 25R centrifuge from Beckman Coulter (Indianapolis, IN) were employed. The Penta-His Antibody from Thermo Scientific (Waltham, MA) was used for Western blot detection. Glucose oxidase from Aspergillus niger $(160 \mathrm{kDa})$ and human serum albumin $(66.5$ $\mathrm{kDa}$ ) were purchased from Sigma-Aldrich (St. Louis, MO). The $n$-octyl $\beta$-D-glucopyranoside (OG) detergent was from Anatrace (Maumee, $\mathrm{OH}$ ). All other chemicals and reagents were from Fisher Scientific (Waltham, MA).

Protein Expression. The recombinant CidC protein (UniProt entry Q6PST7, with a C-terminal histidine tag) was expressed in E. coli BL21(DE3) using a plasmid described previously. ${ }^{15}$ Batches of $750 \mathrm{~mL}$ bacterial cultures were grown in $3 \mathrm{~L}$ baffled flasks using $2 \times$ TY medium $(16 \mathrm{~g} / \mathrm{L}$ tryptone, 10 $\mathrm{g} / \mathrm{L}$ yeast extract, and $5 \mathrm{~g} / \mathrm{L}$ sodium chloride supplemented with $0.1 \mathrm{mg} / \mathrm{mL}$ kanamycin) at $37{ }^{\circ} \mathrm{C}$ while being shaken at $200 \mathrm{rpm}$ in an Excella E24 incubator (Eppendorf, Hamburg, Germany). Bacterial growth was monitored by measuring light scattering at $600 \mathrm{~nm}\left(\mathrm{OD}_{600}\right)$ with a NanoDrop 2000c ultraviolet-visible (UV-vis) spectrophotometer (Thermo Scientific). Protein production was induced by the addition of $1 \mathrm{mM}$ isopropyl $\beta$-D-1-thiogalactopyranoside when the $\mathrm{OD}_{600}$ reached 3 and was performed for $4 \mathrm{~h}$ at $37^{\circ} \mathrm{C}$ when the $\mathrm{OD}_{600}$ reached approximately 6 . Cells were collected by centrifugation at $5000 \mathrm{rpm}$ for $15 \mathrm{~min}$ at $4{ }^{\circ} \mathrm{C}$ using a TS-5.1-500 rotor and then stored at $-20{ }^{\circ} \mathrm{C}$ until further processing.

Protein Purification. Frozen cells were thawed and resuspended in TS8 buffer $[20 \mathrm{mM}$ Tris and $500 \mathrm{mM} \mathrm{NaCl}$ ( $\mathrm{pH} 8.0)$ ]. Cell lysis was induced by the addition of $0.25 \mathrm{mg} /$ $\mathrm{mL}$ lysozyme, $5 \mu \mathrm{g} / \mathrm{mL}$ nuclease, $1 \%(\mathrm{w} / \mathrm{w}$ ) Triton X-100, and $1 \mathrm{mM}$ phenylmethanesulfonyl fluoride while the cell suspension was being stirred at $25{ }^{\circ} \mathrm{C}$ for $30 \mathrm{~min}$. Lysis was completed by sonication using four, $30 \mathrm{~s}$ pulses on ice via a $15 \mathrm{~W}$ Microtip on a Misonix Sonicator 3000 (Misonix Inc., Farmingdale, NY).
Insoluble material was discarded by centrifugation at $7500 \mathrm{rpm}$ and $4{ }^{\circ} \mathrm{C}$ for $30 \mathrm{~min}$ in a TA-14 rotor. Protein purification was immediately performed using a two-step strategy. First, detergent-solubilized cells were loaded onto a $25 \mathrm{~mL}$ HisPrep FF affinity column in TS8 buffer. The column was then washed with $100 \mathrm{~mL}$ of TS8 buffer containing $20 \mathrm{mM}$ imidazole, and the His-tagged CidC was finally eluted with TS8 buffer containing $300 \mathrm{mM}$ imidazole. The protein solution was immediately supplemented with $15 \%$ glycerol and stored in aliquots at $-20{ }^{\circ} \mathrm{C}$ until it was needed. Second, just before the experiments were performed, CidC was further purified by gel filtration using a Superdex 200 Increase 10/300 GL column in $200 \mathrm{mM}$ sodium phosphate buffer $(\mathrm{pH} 7.0)$. The enzyme concentration was estimated via the UV-vis method with an extinction coefficient of $11026 \mathrm{~cm}^{-1} \mathrm{M}^{-1}$ (at $450 \mathrm{~nm}$, corresponding to $\mathrm{FAD}$ absorption), which provides a more accurate determination of the active portion of the CidC sample. Protein purification and all experiments were conducted at $25^{\circ} \mathrm{C}$.

Liposome Preparation. Small phospholipid vesicles were formulated using a 7:3 (w/w) mixture of 1-palmitoyl-2-oleoylsn-glycero-3-[phospho-rac-(1-glycerol)] (POPG) and 1-palmitoyl-2-oleoyl-sn-glycero-3-phosphocholine (POPC) lipids (Avanti Polar Lipids, Alabaster, AL). The lipids were weighed and thoroughly dissolved in sodium phosphate buffer $(\mathrm{pH} 7.0)$ containing $60 \mathrm{mM}$ OG detergent by being incubated for $15 \mathrm{~min}$ at $37{ }^{\circ} \mathrm{C}$ until the solution was clear. Liposomes were then formed via 10 -fold dilution of the lipid/detergent solution mentioned above into sodium phosphate buffer ( $\mathrm{pH}$ 7.0) while it was being mixed vigorously, followed by detergent removal via overnight dialysis against sodium phophate buffer $(\mathrm{pH} 7.0)$ using Spectra/Por 6 dialysis membranes with a $10 \mathrm{kDa}$ cutoff (Spectrum Laboratories, Rancho Dominguez, CA). The liposomes were finally extruded 11 times through $400 \mathrm{~nm}$ Whatman nuclepore track-etched membranes (GE Healthcare) using a Mini-Extruder (Avanti Polar Lipids) and used immediately.

Ferricyanide Assay for CidC Activity. Two micromolar CidC (with urea, Triton X-100, OG, citrate, or liposomes added as indicated) was first incubated with $20 \mathrm{mM}$ pyruvate, $10 \mu \mathrm{M} \mathrm{TPP}$, and $1 \mathrm{mM} \mathrm{Mg}^{2+}$ in sodium phosphate buffer $(\mathrm{pH}$ 6.0) for $20 \mathrm{~min}$. Eight millimolar ferricyanide was then added, and its reduction was immediately visible as it lost its color. Consequently, the CidC activity was measured as a decrease in absorption at $450 \mathrm{~nm}$ over time. The $\mathrm{pH}$-dependent CidC activity was similarly tested in the presence of $200 \mathrm{mM}$ sodium acetate over a $\mathrm{pH}$ range of 5.0-5.6 and $200 \mathrm{mM}$ sodium phosphate buffer over a $\mathrm{pH}$ range of 5.6-8.0. The enzyme activity was identical at $\mathrm{pH} 5.6$ in both sodium acetate and sodium phosphate. One unit of pyruvate oxidoreductase activity is defined as the amount of enzyme required to consume 1 $\mu$ mol of pyruvate in $1 \mathrm{~min}$. The CidC specific activity was estimated accordingly within $1 \mathrm{~min}$ of the ferricyanide addition, taking into account the facts that (i) 2 equiv of ferricyanide is reduced per equivalent of decarboxylated pyruvate and (ii) the extinction coefficient of ferricyanide at $450 \mathrm{~nm}$ is $0.218 \mathrm{mM}^{-1}$ $\mathrm{cm}^{-1}$.

Acetate Quantification. The "Acetic Acid Test Kit" (RBiopharm AG, Darmstadt, Germany) was employed using the provided instructions to measure acetate concentrations. Protein samples of $2 \mu \mathrm{M}$ CidC alone, or $2 \mu \mathrm{M}$ CidC supplemented with either $0.05 \%$ Triton X-100 or $3 \mathrm{M}$ urea, were first incubated with $20 \mathrm{mM}$ pyruvate, $10 \mu \mathrm{M}$ TPP, and 1 
$\mathrm{mM} \mathrm{Mg}^{2+}$ in sodium phosphate buffer ( $\mathrm{pH} \mathrm{6.0)}$ for $20 \mathrm{~min}$. Eight millimolar sodium ferricyanide was then added, and the acetate levels were measured in triplicate after $30 \mathrm{~min}$ when the reaction was completed. The urea-containing sample was used as a negative control, while a $5 \mathrm{mM}$ acetate solution was used as a positive control.

$\mathrm{H}_{2} \mathrm{O}_{2}$ Quantification. Peroxidase catalyzes the reaction of $\mathrm{H}_{2} \mathrm{O}_{2}$ with 4-aminoantipyrine and phenol to form 4- $(p$ benzoquinone-monoimino)-phenazone with a $510 \mathrm{~nm}$ absorbance proportional to the initial $\mathrm{H}_{2} \mathrm{O}_{2}$ concentration. ${ }^{20,28,29}$ This reaction was calibrated for $\mathrm{H}_{2} \mathrm{O}_{2}$ quantification in the range of $1-10 \mathrm{mM}\left(R^{2}=0.99\right)$. Twenty millimolar pyruvate, $10 \mu \mathrm{M}$ $\mathrm{TPP}$, and $1 \mathrm{mM} \mathrm{Mg}{ }^{2+}$ were incubated with $2 \mu \mathrm{M}$ CidC alone, or $2 \mu \mathrm{M}$ CidC supplemented with either $0.05 \%$ Triton $\mathrm{X}-100$ or $3 \mathrm{M}$ urea in sodium phosphate buffer ( $\mathrm{pH} \mathrm{6.0)}$ for $20 \mathrm{~min}$, after which $35 \mathrm{mM}$ phenol, $10 \mathrm{mM}$ 4-aminoantipyrine, and 1 $\mu \mathrm{M}$ horseradish peroxidase were added. The activity of glucose oxidase was used as a positive control because it converts glucose to gluconolactone and $\mathrm{H}_{2} \mathrm{O}_{2}$.

CidC Quinone Electron Transport Assay. These experiments were conducted like the ferricyanide assay, except that the $8 \mathrm{mM}$ ferricyanide was replaced with $250 \mu \mathrm{M}$ MN0 or CoenzymeQ (CoQ0) [the headgroups of either menaquinone or ubiquinone, respectively, from a dimethyl sulfoxide (DMSO) stock] and $80 \mu \mathrm{M}$ cytochrome $c$. The cytochrome reduction was followed spectroscopically at $550 \mathrm{~nm}$.

Kinetic Analysis. CidC enzyme activity assays were conducted using the electron acceptors mentioned above at concentrations of $\leq 20 \mathrm{mM}$ under specified conditions (different $\mathrm{pH}$ values with or without liposomes). The reactions were spectroscopically monitored for up to $2 \mathrm{~min}$, and the initial reaction velocities were calculated using the data within the first $20 \mathrm{~s} . K_{\mathrm{m}}$ and $k_{\text {cat }}$ parameters were then calculated using the Michaelis-Menten equation.

The $\mathrm{pH}$ dependencies of values of $k_{\text {cat }}$ versus $\mathrm{pH}$ were analyzed according to the rapid equilibrium diprotic model, ${ }^{30}$ which is used if the difference in $\mathrm{p} K_{\mathrm{a}}$ values is $<3.5 \mathrm{pH}$ units. The following expressions were derived for $k_{\mathrm{cat}}$ and $k_{\mathrm{cat}} / K_{\mathrm{m}}$ :

$$
\begin{aligned}
& \frac{k_{\mathrm{cat}}}{K_{\mathrm{m}}}=\frac{\left(k_{\mathrm{cat}} / K_{\mathrm{m}}\right)^{\mathrm{max}}}{1+\frac{\mathrm{H}^{+}}{K_{\mathrm{H}_{2} \mathrm{E}}}+\frac{K_{\mathrm{HE}}}{\left[\mathrm{H}^{+}\right]}} \\
& k_{\mathrm{cat}}=\frac{\left(k_{\mathrm{cat}}\right)^{\mathrm{max}}}{1+\frac{\mathrm{H}^{+}}{K_{\mathrm{H}_{2} \mathrm{ES}}}+\frac{K_{\mathrm{HES}}}{\left[\mathrm{H}^{+}\right]}}
\end{aligned}
$$

Transmission Electron Microscopy (TEM). Samples were incubated with $5 \mathrm{~nm}$ Ni-NTA-Nanogold (Nanoprobes, Yaphank, NY) to label CidC for $30 \mathrm{~min}$. Ten microliters of the sample was then placed on thin carbon films on holey grids and allowed to absorb for $2 \mathrm{~min}$, after which the grid was washed twice with $10 \mu \mathrm{L}$ of deionized water and negatively stained with methylamine vanadate. Imaging was performed with a Tecnai G2 transmission electron microscope (FEI) operated at $80 \mathrm{kV}$.

Isothermal Titration Calorimetry (ITC). ITC was performed on a MicroCal iTC200 instrument (Malvern Instruments Ltd., Worcestershire, U.K.). Forty microliters of $100 \mu \mathrm{M}$ CidC in sodium phosphate buffer ( $\mathrm{pH} 7.0)$ was injected into $250 \mu \mathrm{L}$ of $200 \mathrm{mM}$ sodium phosphate ( $\mathrm{pH} 6.0$ ) buffer containing various ingredients as specified. A total of 20 injections ( $2 \mu \mathrm{L}$ each, spaced by $5 \mathrm{~min}$ ) were performed at room temperature. Data were analyzed using the Origin software (OriginLab Corp., Northampton, MA).

Tryptophan Fluorescence Titration. Purified CidC in sodium phosphate buffer $(\mathrm{pH} 7.0)$ was diluted in either $\mathrm{pH} 6.0$ or 7.0 sodium phosphate buffer to a final concentration of 850 $\mu \mathrm{M}$ in $1.3 \mathrm{~mL}$. TPP was then added in $1.5 \mu \mathrm{L}$ increments from a $100 \mu \mathrm{M}$ stock in water, and the solution was mixed for $30 \mathrm{~s}$. At each increment, the tryptophan fluorescence $(280 \mathrm{~nm}$ excitation, $340 \mathrm{~nm}$ emission) was measured with a Spex Fluorlog 322 fluorescence spectrophotometer (Jobin Yvon, Edison, $\mathrm{NJ}$ ) in a $1500 \mu \mathrm{L}$ stirred quartz cuvette at $25^{\circ} \mathrm{C}$. Data were processed using the Origin software (OriginLab Corp.).

Protease Treatment. Two micromolar CidC in $200 \mathrm{mM}$ sodium phosphate buffer ( $\mathrm{pH} 6.0$ or 7.0 ) containing either 20 $\mathrm{mM}$ pyruvate, $10 \mu \mathrm{M} \mathrm{TPP}$, or $1 \mathrm{mM} \mathrm{Mg}^{2+}$ was incubated for 30 min. One micromolar trypsin or chymotrypsin was then added, and proteolytic cleavage was conducted for $30 \mathrm{~min}$. The solution was immediately tested for activity using the ferricyanide assay or immediately precipitated using a 4:1 ( $\mathrm{v} /$ v) methanol/chloroform solution and studied by sodium dodecyl sulfate-polyacrylamide gel electrophoresis (SDSPAGE).

\section{RESULTS}

To study the $S$. aureus CidC enzyme, a previously established expression plasmid ${ }^{15}$ was used to generate milligram amounts of purified protein. Initial screening using Western blot analysis of the C-terminal histidine tag of CidC showed that E. coli BL21(DE3) cells containing this plasmid produce large quantities of this enzyme (data not shown). A first-step affinity chromatography procedure employing Ni-NTA resin resulted in pure and stable protein in $200 \mathrm{mM}$ phosphate buffer $(\mathrm{pH} 8)$ containing $500 \mathrm{mM} \mathrm{NaCl}$ and $300 \mathrm{mM}$ imidazole (Figure 1A). As expected for flavoproteins, CidC exhibited characteristic UV-vis absorption at 380 and $450 \mathrm{~nm}$ and fluorescence at 530 $\mathrm{nm}$ (with $450 \mathrm{~nm}$ excitation) as shown in Figure 1B. ${ }^{28,31}$ The intrinsic fluorescence of CidC was observed at $340 \mathrm{~nm}$ (with $280 \mathrm{~nm}$ excitation), which is also shown in Figure $1 \mathrm{~B}^{31}$ Via measurement of the $A_{280}$ (the protein peak) and $A_{450}\left(\mathrm{FADH}_{2}\right.$ peak), it was determined that at least $80 \%$ of CidC binds FAD; thus, no attempt to supplement this flavoprotein with FAD was made in subsequent experiments. The CidC molecular weight (calculated average of $64806 \mathrm{Da}$ ) was qualitatively confirmed by SDS-PAGE (Figure 1A) and quantitatively by mass spectrometry within a few daltons (data not shown). The first five amino acids (Ala, Lys, Ile, Lys, and $\mathrm{Ala}$ ) were verified by $\mathrm{N}$-terminal sequencing (data not shown), strongly confirming the identity of the purified protein (the first methionine was cleaved during expression in E. coli). The protein solution was mixed with $20 \%(\mathrm{v} / \mathrm{v})$ glycerol and stored at $-20{ }^{\circ} \mathrm{C}$ until experiments were performed.

As demonstrated below, the recombinant CidC protein is active only between $\mathrm{pH} 5$ and 6.5; however, it also precipitates rapidly at acidic $\mathrm{pH}$. The addition of high concentrations of arginine and $\mathrm{NaCl}$ delays protein self-aggregation, but these additives were also found to inhibit the enzymatic activity of this protein. A NaCl-free and neutral solution is therefore required to maintain a stable CidC preparation. To achieve this, an additional purification step was implemented to decrease the $\mathrm{pH}$ and $\mathrm{NaCl}$ content of the CidC preparation by performing gel filtration chromatography in $200 \mathrm{mM}$ phosphate buffer $(\mathrm{pH}$ 7) without $\mathrm{NaCl}$ (Figure 1C). The CidC sample can then be diluted or titrated into a more acidic buffer to perform activity 


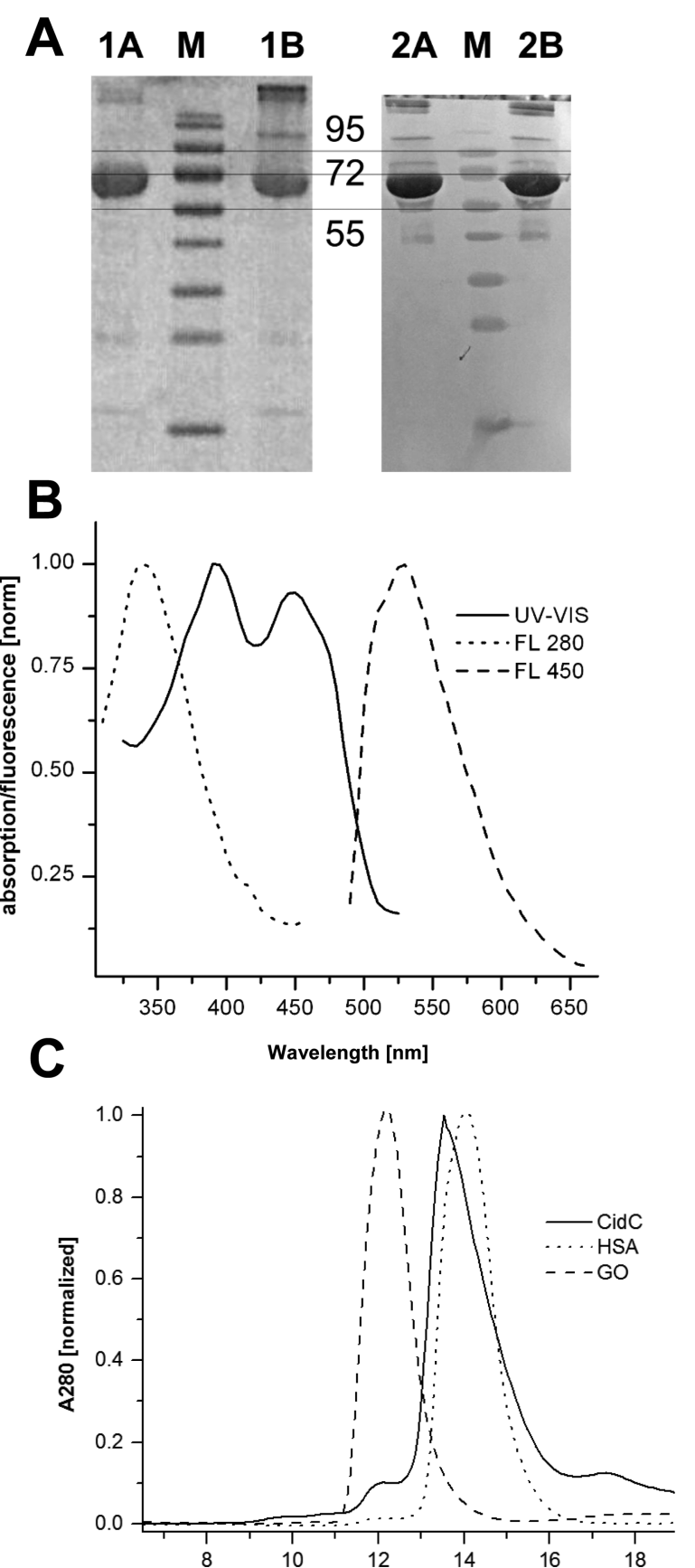

Figure 1. CidC purification and optical characterization. (A) SDSPAGE gel (left) and Western blot (right) of purified CidC in the presence (lanes $1 \mathrm{~A}$ and $2 \mathrm{~A}$ ) or absence (lanes $1 \mathrm{~B}$ and $2 \mathrm{~B}$ ) of $\beta$ mercaptoethanol. Relevant bands in the marker lanes (M) are identified by their molecular weight in kilodaltons. (B) UV-vis and fluorescence with excitation at $280 \mathrm{~nm}$ (FL 280) and $450 \mathrm{~nm}$ (FL 450) spectra of CidC at pH 7. (C) Purification of proteins. CidC, human serum albumin (HSA), and glucose oxidase (GO) were each separately purified. The asterisk denotes CidC dimers.

assays. This protein formulation provided consistent results among different protein batches while also minimizing the effect of self-aggregation.

Interaction of CidC with Phospholipid Membranes. The E. coli pyruvate:quinone oxidoreductase, PoxB, exists in a soluble and inactive form within the cytoplasm and becomes active upon binding to the cellular membrane..$^{25,32-35}$ To study the interaction of CidC with membranes, liposomes prepared with a simple 7:3 (w/w) POPG/POPC mixture were used to mimic the cytoplasmic membrane lipid composition of $S$. aureus. $^{36,37}$ Three samples containing (i) CidC, (ii) liposomes, and (iii) a CidC/liposome mixture were subjected to the same gel filtration procedure described above in $200 \mathrm{mM}$ sodium phosphate buffer ( $\mathrm{pH} \mathrm{6)}$ (Figure 2A). Because of their large
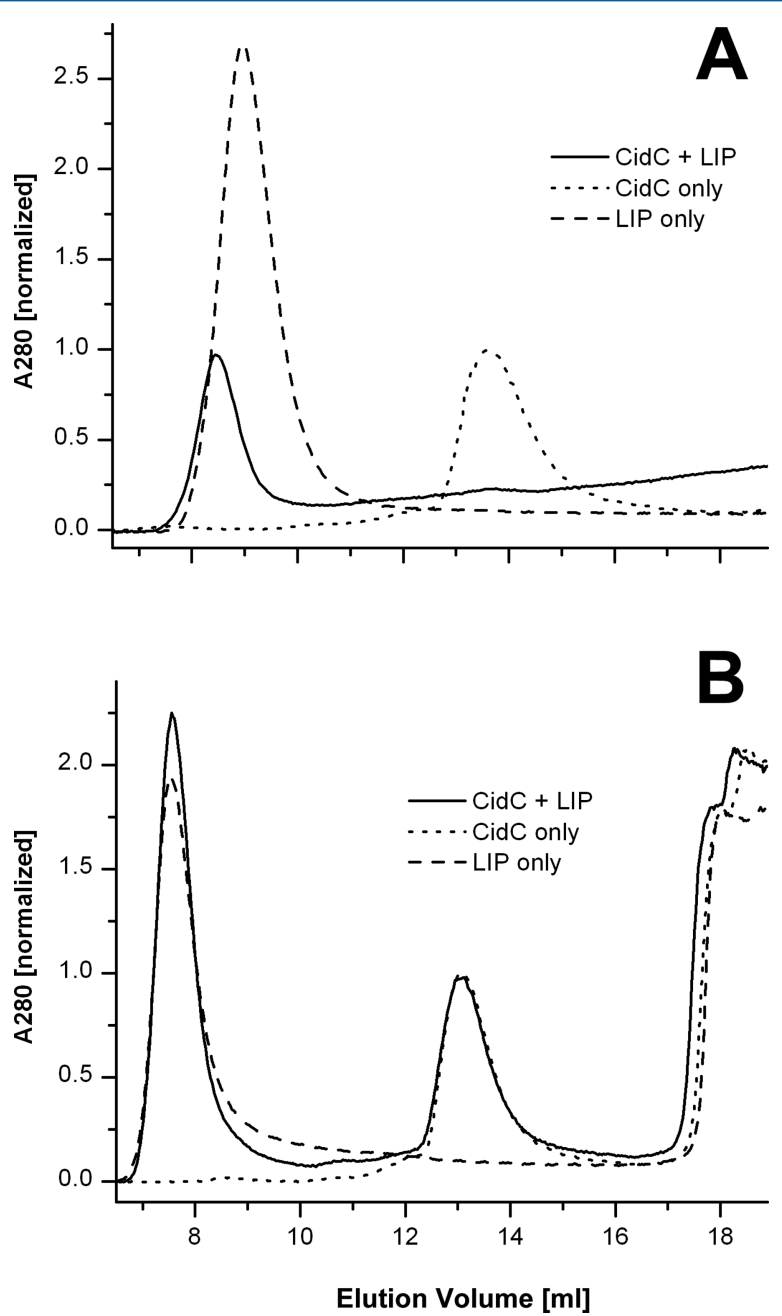

Figure 2. Interaction of CidC with liposomes as determined by gel filtration. (A) CidC, liposomes (LIP), and their mixture were purified. The asterisk denotes a minute amount of monomeric CidC eluting from the CidC/LIP mixture. (B) Like panel A, except that $500 \mathrm{mM}$ $\mathrm{NaCl}$ was used during purification. The asterisk denotes the elution of small molecules (e.g., salts, residual detergents, etc.). The inclusion of a high salt concentration slightly changes the physical properties of the column; e.g., the void volume and monomeric CidC elution are shifted compared to those of panel A. Data were scaled relative to the protein $A_{280}$ in all cases.

dimensions, the liposomes elute in the void volume and also scatter light, which translated into an apparent absorption at $280 \mathrm{~nm}$. The peak corresponding to the CidC monomer disappears completely when the CidC/liposome mixture is analyzed, suggesting that CidC co-elutes with the liposomes. The sum of the $A_{280}$ signals generated by the liposomes and CidC alone is significantly larger than the signal obtained when the mixture is injected, suggesting that CidC not only binds to the membranes but also aggregates with the liposomes into much larger assemblies that are trapped on the column and do not elute at all. To test this, the CidC membrane binding 


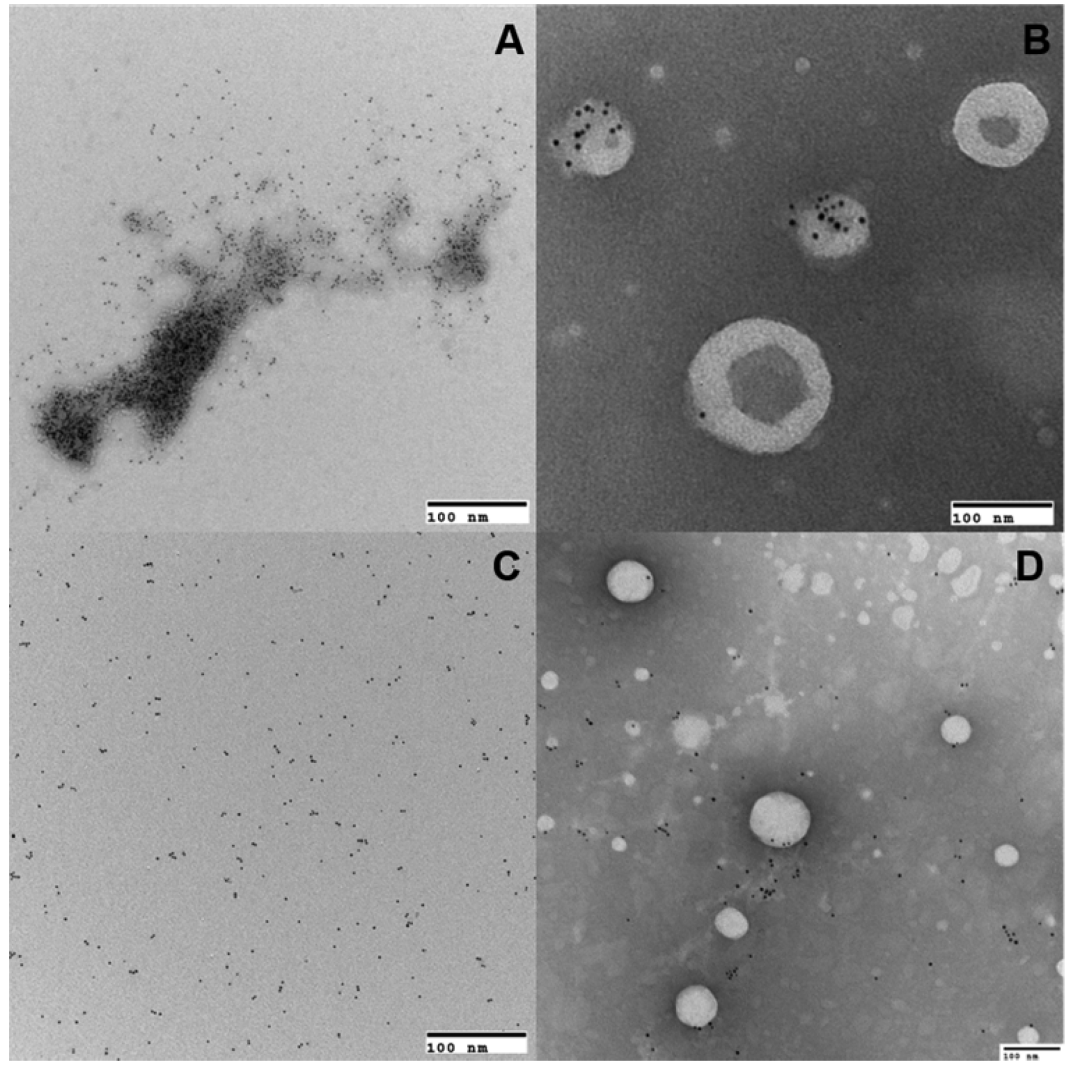

Figure 3. TEM characterization of CidC. TEM images showing CidC as labeled by $5 \mathrm{~nm}$ nanogold particles and liposomes by negative staining. CidC in $200 \mathrm{mM}$ sodium phosphate buffer ( $\mathrm{pH}$ 6) was mixed either (A) without liposomes or (B) with liposomes. Similarly, CidC in $200 \mathrm{mM}$ sodium phosphate buffer ( $\mathrm{pH}$ 7) was mixed (C) either without liposomes or (D) with liposomes.

experiment was repeated with $500 \mathrm{mM} \mathrm{NaCl}$ added to the running buffer as shown in Figure 2B. Under these conditions, CidC elutes independently from the liposomes when the $\mathrm{CidC} /$ liposome mixture is injected. The experiment repeated in sodium phosphate buffer $(\mathrm{pH} 7)$ generates a result similar to that of the $\mathrm{pH} 6$ buffer with $500 \mathrm{mM} \mathrm{NaCl}$, indicating that CidC interacts with the liposomes to a much lesser extent at pH 7 (data not shown).

The interaction of CidC with membranes was further probed by TEM. As shown in Figure 3C, purified nanogold-labeled CidC protein aggregates at $\mathrm{pH} 6$ (Figure $3 \mathrm{~A}$ ) but remains a monomer at $\mathrm{pH} 7$ (Figure 3C). When liposomes were added, CidC/liposome co-localization was observed only at $\mathrm{pH} 6$ (Figure 3B). Very large structures were also observed at $\mathrm{pH} 6$, most likely representing CidC-liposome aggregates in agreement with the gel filtration data presented above (data not shown). When the cofactors TPP and $\mathrm{Mg}^{2+}$ were added to the sample, the same co-localization was observed, indicating that the presence of cofactors alone does not promote the localization of CidC to the membrane if the $\mathrm{pH}$ is not optimal. As expected, CidC does not co-localize with liposomes (or binds very weakly) in $\mathrm{pH} 7$ buffer, as shown in Figure 3D, also consistent with the results generated using gel filtration chromatography. Combined, the data given above demonstrate that CidC spontaneously binds to membranes at acidic $\mathrm{pH}$ and that this interaction is mostly electrostatic in nature.

CidC Converts Pyruvate to Acetate in Vitro. Two possible enzymatic reactions are catalyzed by pyruvate oxidoreductases: one converts pyruvate to acetate and carbon dioxide and the other to acetyl phosphate and hydrogen peroxide. The reactions can be identified by detecting acetate and hydrogen peroxide, respectively, as the reaction end products. A note is made that this reaction requires a quinone, which was substituted with ferricyanide, and that the acetyl phosphate pathway requires phosphate and oxygen, which were present in the sodium phosphate buffer. Previous studies have shown that pyruvate:quinone oxidoreductases are minimally active in the absence of amphiphiles such as Triton X-100 detergent or phospholipids. $^{21,38,39}$ For this reason, Triton X100 was incorporated into some of the assays to potentially activate CidC. Tests were initially performed at $\mathrm{pH} 6$, which provides a good compromise between the $\mathrm{pH}$ optimal for CidC activity and self-aggregation; however, some pyruvate:quinone oxidoreductases exhibit a strong $\mathrm{pH}$-dependent activity. ${ }^{20}$ To ensure that $\mathrm{CidC}$ does not produce hydrogen peroxide at a different $\mathrm{pH}$, a wide $\mathrm{pH}$ range was screened.

CidC was incubated for $1 \mathrm{~h}$ with pyruvate, the TPP $/ \mathrm{Mg}^{2+}$ cofactor, and the artificial electron acceptor ferricyanide in sodium phosphate buffer ( $\mathrm{pH} \mathrm{6)}$ to allow for the complete enzymatic conversion of pyruvate by CidC. Initial tests showed that the reaction reaches completion within several minutes under the conditions utilized and that longer incubation times do not change the enzymatic outcome. This solution was then tested for the presence of acetate and hydrogen peroxide. Acetate was quantitatively confirmed in the CidC enzymatic end products (Figure S1A). Two equivalents of ferricyanide is reduced per equivalent of decarboxylated pyruvate by pyruvate oxidases. ${ }^{38}$ In this case, $20 \mathrm{mM}$ pyruvate and $8 \mathrm{mM}$ ferricyanide were used, making ferricyanide the reaction-limiting reactant. If all of the pyruvate is converted to acetate, the final acetate 
concentration is expected to be half that of ferricyanide (or $\sim 4$ $\mathrm{mM}$ ). An average value of $4.48 \pm 0.01 \mathrm{mM}$ acetate was indeed measured, suggesting that CidC efficiently converted all pyruvate to acetate under these conditions. Inclusion of $1 \%$ (w/v) Triton X-100 did not significantly affect the reaction; inclusion of $3 \mathrm{M}$ urea severely limited the generation of acetate, and stoichiometric substitution of CidC with lysozyme in this experiment resulted in no detectable acetate production. Hydrogen peroxide was absent from the end products of the CidC-catalyzed reaction (Figure S1B), even when $1 \%(\mathrm{w} / \mathrm{v})$ Triton X-100 was added to the reaction mixture. The CidC catalytic reaction described above was also conducted across a $\mathrm{pH}$ range of 5-8; however, hydrogen peroxide could not be detected in any of these assays.

Modulators of CidC Enzymatic Activity. Previous studies of E. coli PoxB and C. glutamicum PQO showed that these enzymes can be activated by amphiphiles, including both detergent and phospholipids, and are minimally active in their absence. $^{21,35,39,40}$ To test whether CidC exhibits similar properties, the effects of detergents and lipids on the CidC enzymatic activities were investigated. CidC was incubated with pyruvate, TPP $/ \mathrm{Mg}^{2+}$, and several activity modulators. The enzymatic reactions were initiated by the addition of ferricyanide and monitored by following its reduction via the change in absorbance at $450 \mathrm{~nm}$. On the basis of the calculated initial rates of enzymatic activity, Triton X-100, as well as the milder detergent, OG, did not alter enzyme activity even when added at high concentrations (Table 1). However, the presence

Table 1. CidC Activity Modulators

\begin{tabular}{clll} 
protein/enzyme & modulator & \multicolumn{1}{c}{ concentration } & $\begin{array}{c}\text { initial rate } \\
(\mathrm{mM} / \mathrm{s})\end{array}$ \\
\hline CidC $(0.78 \mu \mathrm{M})$ & $\mathrm{NA}$ & $\mathrm{NA}$ & $0.14 \pm 0.03$ \\
& Triton & $1 \%(\mathrm{v} / \mathrm{v})$ & $0.16 \pm 0.03$ \\
& $\mathrm{X}-100$ & & $0.16 \pm 0.02$ \\
& Triton & $0.05 \%(\mathrm{v} / \mathrm{v})$ & \\
& $\mathrm{X}-100$ & & 0 \\
& urea & $3 \mathrm{M}($ preincubated for & \\
& & $10 \mathrm{~min})$ & $0.15 \pm 0.01$ \\
& OG & $5 \mathrm{mM}$ & $0.31 \pm 0.03$ \\
& liposome & $0.5 \mathrm{mg} / \mathrm{mL}$ & $0.13 \pm 0.01$ \\
& $\mathrm{NaCl}$ & $50 \mathrm{mM}$ & $0.09 \pm 0.01$ \\
& $\mathrm{NaCl}$ & $100 \mathrm{mM}$ & $0.04 \pm 0.02$ \\
$(0.78 \mu \mathrm{M})$ & $\mathrm{NaCl}$ & $250 \mathrm{mM}$ & $0.02 \pm 0.01$ \\
\hline & $\mathrm{NaCl}$ & $500 \mathrm{mM}$ & 0 \\
\hline
\end{tabular}

of $7: 3(\mathrm{w} / \mathrm{w})$ POPG/POPC liposomes, which mimic the $S$. aureus membrane, induced a 3 -fold increase in the initial velocity $(0.31 \pm 0.03 \mathrm{mM} / \mathrm{s})$. As expected, the presence of $3 \mathrm{M}$ urea resulted in no ferricyanide reduction.

Because $\mathrm{NaCl}$ impaired $\mathrm{CidC}$ self-aggregation and interaction with membranes, its effect on CidC catalysis was also investigated. $\mathrm{NaCl}$ was able to inhibit CidC activity in a dosedependent manner (Table 1). At higher concentrations, the effect was much more pronounced, almost completely abolishing the enzymatic activity. The effect of $\mathrm{NaCl}$ is likely to be a function of the $\mathrm{Cl}^{-}$ion because $\mathrm{Na}^{+}$was present in the buffer at $200 \mathrm{mM}$. The results of these experiments suggest that CidC activity is enhanced by interacting with phospholipid membranes, but not by non-ionic detergents, and that these interactions are likely to be electrostatic in nature.
CidC Activity Is Strongly pH-Dependent. To investigate the $\mathrm{pH}$ optimum of CidC activity, the specific decarboxylation activity of $\mathrm{CidC}$ at different $\mathrm{pH}$ values was measured using ferricyanide as the electron acceptor, as shown in Figure 4A. It was found that $\mathrm{CidC}$ reaches the maximum catalytic activity from $\mathrm{pH} 5.4$ to 5.8 and is minimally active at or above $\mathrm{pH}$ 7. It is worth noting that this experiment was repeated using sodium acetate buffer from $\mathrm{pH} 5.4$ to 5.6, confirming that CidC is not a phosphate-dependent pyruvate oxidase like POX from $L$. plantarum.

The enzymatic kinetic parameters of CidC were also determined at four different $\mathrm{pH}$ values $(5.2,5.6,6$, and 7$)$, in the presence and absence of $7: 3(\mathrm{w} / \mathrm{w})$ POPG/POPC liposomes. As shown in Figure $4 \mathrm{~B}-\mathrm{D}$, CidC has the lowest $K_{\mathrm{m}}$, the highest $k_{\text {cat }}$, and, thus, the highest catalytic efficiency, $k_{\text {cat }} / K_{\mathrm{m}}\left(1144 \pm 124 \mathrm{M}^{-1} \mathrm{~s}^{-1}\right)$, for pyruvate at $\mathrm{pH} 5.6$ in the absence of liposomes. When liposomes are added, the $K_{\mathrm{m}}$ does not change substantially at acidic $\mathrm{pH}$ but decreases by 3 -fold at $\mathrm{pH} 7$ (Figure 4B). The $k_{\text {cat }}$ value also reaches its peak at $\mathrm{pH} 5.6$ in the presence of liposomes (Figure 4C), which is 10 times higher than that without liposomes, as is reflected in the $k_{\text {cat }} / K_{\mathrm{m}}$ value (Figure 4D). These results demonstrate that in the optimum working $\mathrm{pH}$ range, interactions of $\mathrm{CidC}$ with liposomes greatly increase the turnover rate of this enzyme with pyruvate but have a very limited effect on its binding affinity for CidC.

Moreover, the $\mathrm{pH}$ dependence of $k_{\text {cat }}$ (Figure 4C) and $k_{\text {cat }} /$ $K_{\mathrm{m}}$ (Figure 4D) plots further generates the $\mathrm{p} K_{\mathrm{a}}$ values for the enzyme-substrate complex and free enzyme, as shown in Table S1. The data were modeled using eqs I and 2, where $K_{\mathrm{HE}}$ and $K_{\mathrm{H}_{2} \mathrm{E}}$ are the ionization constants for the free enzyme and $K_{\mathrm{HES}}$ and $\mathrm{K}_{\mathrm{H}_{2} \mathrm{ES}}$ are the ionization constants for the ES complex (see Experimental Procedures). The differences in the observed values can be attributed to CidC because there is no ionizable group in the substrate, pyruvate $\left(\mathrm{pK}_{\mathrm{a}}=2.5\right)$. Also, the range of $\mathrm{p} K_{\mathrm{HE}}$ and $\mathrm{p} K_{\mathrm{H}_{2} \mathrm{E}}$ values in the absence of liposomes $(5.4-5.6)$ is relatively narrow compared to that in the presence of liposomes (5.1-5.9), suggesting that binding to liposomes causes slight changes in the protonation profile of the CidC binding pocket that stimulates its activity.

CidC Binds Its TPP/ $\mathrm{Mg}^{2+}$ Cofactor Only at Acidic $\mathrm{pH}$. To test the interaction of CidC with its cofactors, ITC experiments were performed. The interaction between CidC and $\mathrm{TPP} / \mathrm{Mg}^{2+}$ was specifically characterized at $\mathrm{pH} 6$, where CidC is active, and $\mathrm{pH} \mathrm{7,} \mathrm{where} \mathrm{CidC} \mathrm{is} \mathrm{not} \mathrm{active.} \mathrm{CidC} \mathrm{in}$ sodium phosphate ( $\mathrm{pH} 7$ ) buffer (to minimize self-aggregation) was loaded into the ITC syringe and titrated into buffers containing TPP and TPP $/ \mathrm{Mg}^{2+}$. A strong exothermic interaction between CidC and $\mathrm{TPP} / \mathrm{Mg}^{2+}$ was observed in $\mathrm{pH} 6$ buffer, but the extent of this reaction was significantly lower in the absence of $\mathrm{Mg}^{2+}$ at $\mathrm{pH} 7$ (Figure S2). The results of these studies suggest that the $\mathrm{pH}$ dependence of $\mathrm{CidC}$ is due to the differential binding of $\mathrm{TPP} / \mathrm{Mg}^{2+}$, and that $\mathrm{Mg}^{2+}$ facilitates the binding of TPP, which is consistent with other studies. $^{41-43}$

Limited by the self-aggregation of $\mathrm{CidC}$ at acidic $\mathrm{pH}$, we could not measure the $K_{\mathrm{d}}$ or enthalpy of binding using ITC. Instead, we used a fluorescence quenching assay to determine those parameters, as intrinsic fluorescence-based assays are more sensitive and require much less protein, thereby avoiding the rapid aggregation of CidC. Under the test conditions used here, CidC remained stable at $\mathrm{pH} 6$ for the duration of the 

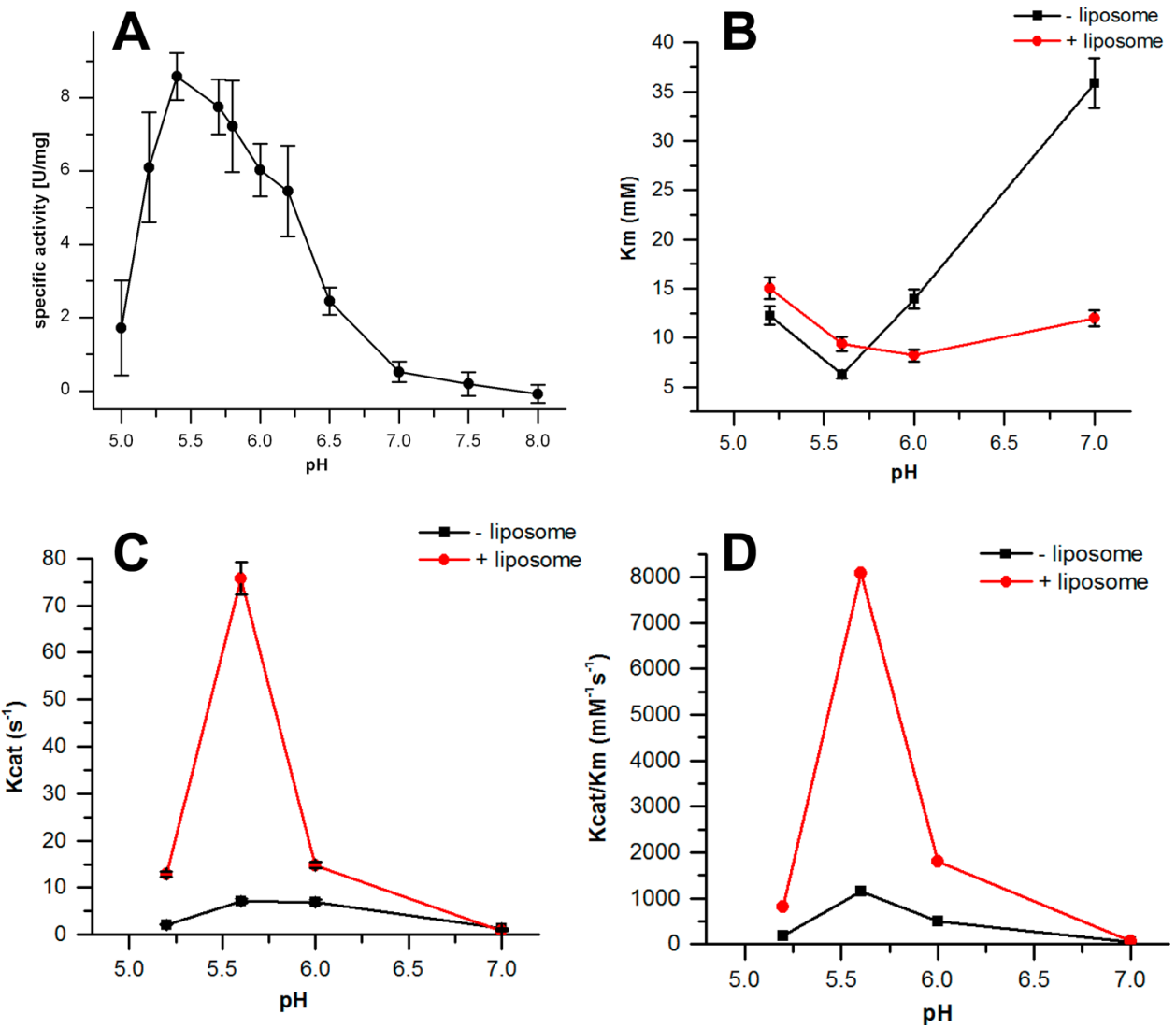

Figure 4. $\mathrm{pH}$ dependence of CidC activity. The kinetic profile of CidC catalysis at different $\mathrm{pHs}$ as monitored by the ferricyanide assay. (A) Calculated CidC specific activity as a function of $\mathrm{pH}$ from $\mathrm{pH} 5$ to 8. (B) Calculated $K_{\mathrm{m}}$ as a function of $\mathrm{pH}$ at $\mathrm{pH}$ 5.2, 5.6, 6.0, and 7.0. (C) Calculated $k_{\text {cat }}$ as a function of $\mathrm{pH}$ at $\mathrm{pH} 5.2,5.6,6.0$, and 7.0. (D) Calculated $k_{\text {cat }} / K_{\mathrm{m}}$ as a function of $\mathrm{pH}$ at $\mathrm{pH} 5.2,5.6,6.0$, and 7.0.
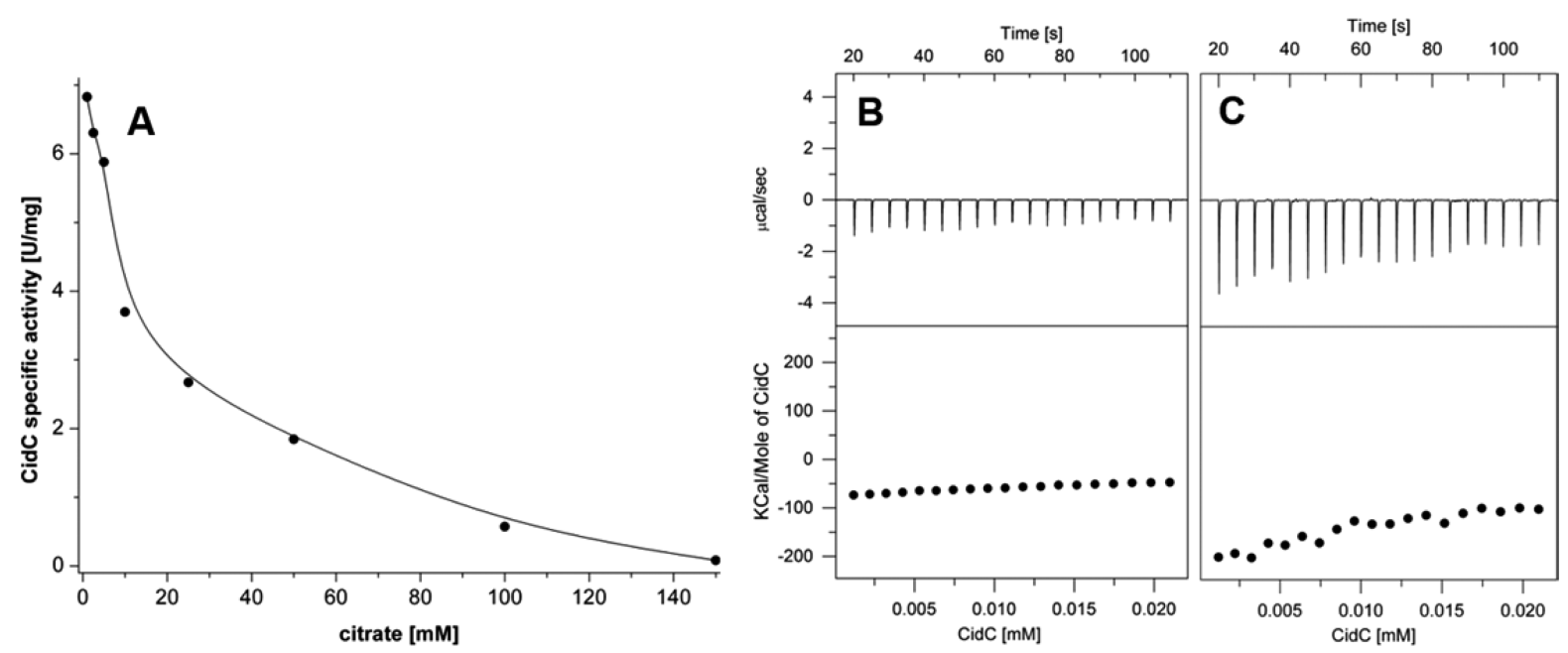

Figure 5. Citrate inhibition of CidC. (A) CidC specific activity in the presence of citrate in pH 6 buffer measured by the ferricyanide assay. ITC experiments as in Figure S2, except that CidC was titrated into (B) pyruvate, pH 6 buffer or (C) $10 \mathrm{mM}$ citrate, pH 6 buffer.

experiment. The tryptophan fluorescence of CidC was measured in the presence of various TPP $/ \mathrm{Mg}^{2+}$ concentrations. The fluorescence-concentration relationship was fit to a double-reciprocal plot, to determine the $K_{\mathrm{d}}$ (see Experimental Procedures). It was found that $\mathrm{CidC}$ has the highest binding affinity for TPP in the presence of $\mathrm{Mg}^{2+}$ at $\mathrm{pH} 6\left(K_{\mathrm{d}}=0.3\right.$ $\mu \mathrm{M})$; without $\mathrm{Mg}^{2+}$, the affinity was 10 times lower $\left(K_{\mathrm{d}}=3\right.$ $\mu \mathrm{M})$. However, the $K_{\mathrm{d}}$ was $26.2 \mu \mathrm{M}$ for CidC and TPP with $\mathrm{Mg}^{2+}$ at $\mathrm{pH} 7$, indicating a much lower binding affinity.
Together, these results indicate that CidC binds TPP strongly at acidic $\mathrm{pH}$ and has a very low affinity for TPP at neutral $\mathrm{pH}$. In addition, $\mathrm{Mg}^{2+}$ greatly enhances TPP binding under acidic $\mathrm{pH}$ conditions.

Citrate Inhibits CidC Activity. When testing the $\mathrm{pH}$ dependence of CidC activity, we initially found citrate-based buffers were had a concentration-dependent effect on CidC activity. Further analysis using the ferricyanide-based assay described above demonstrated that citrate inhibits CidC activity 
with an $\mathrm{IC}_{50}$ of $10 \mathrm{mM}$ at $\mathrm{pH} 6.0$ (Figure 5A). ITC experiments similar to those presented above indicate that citrate directly binds to CidC at $\mathrm{pH} 6$ in the absence of pyruvate and TPP/ $\mathrm{Mg}^{2+}$. When CidC was titrated into sodium phosphate ( $\left.\mathrm{pH} 6\right)$ buffer supplemented with $10 \mathrm{mM}$ pyruvate, an exothermic protein structural change of approximately $-50 \mathrm{kcal} / \mathrm{mol}$ of CidC was observed (Figure 5B). However, titration into sodium phosphate ( $\mathrm{pH} \mathrm{6)}$ buffer supplemented with $10 \mathrm{mM}$ citrate revealed a reaction with approximately $-200 \mathrm{kcal} / \mathrm{mol}$ of CidC [in the first injections (Figure 5C)], most likely due to binding of citrate to CidC in addition to the $\mathrm{pH}$-induced CidC conformational change, which is stronger than that of CidC binding to pyruvate.

Truncated CidC Maintains Enzymatic Activity. E. coli PoxB was shown to be activated after treatment with chymotrypsin. ${ }^{25,35,44-46}$ The effects of both trypsin and chymotrypsin were therefore investigated here at $\mathrm{pH} 6$ when CidC is active and at $\mathrm{pH} 7$ when CidC is mostly inactive. The results for trypsin are shown in Figure 6, noting that identical

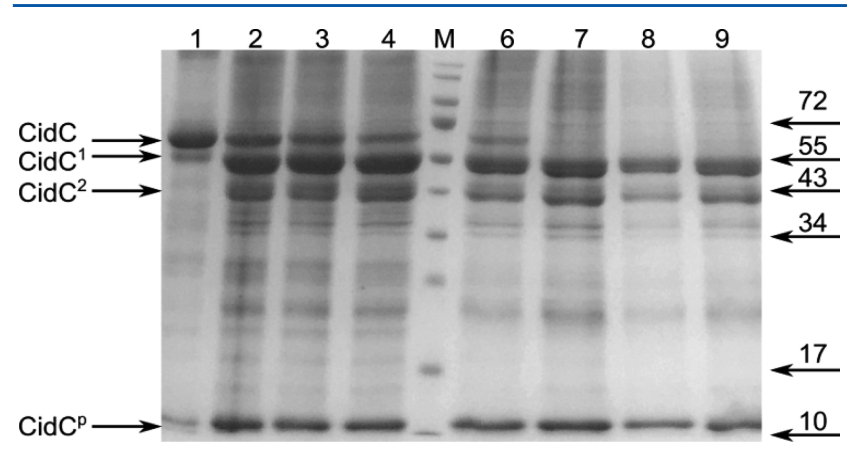

Figure 6. Proteolysis of CidC. SDS-PAGE showing the CidC cleavage products after incubation with trypsin for $30 \mathrm{~min}$ at $\mathrm{pH} 6$ (lanes 1-4) and $\mathrm{pH} 7$ (lanes 6-9). Before proteolysis, CidC was incubated with (lanes 1 and 6) pyruvate, TPP, and $\mathrm{Mg}^{2+}$, (lanes 2 and 7) TPP and $\mathrm{Mg}^{2+}$, (lanes 3 and 8) pyruvate, and (lanes 4 and 9) $\mathrm{Mg}^{2+}$. CidC products are shown at the left with $\mathrm{CidC}^{1}$ and $\mathrm{CidC}^{2}$ being several kilodaltons and $\sim 20 \mathrm{kDa}$, respectively, smaller than CidC, while $\mathrm{CidC}^{\mathrm{p}}$ indicates small peptides. Several bands from the marker (lane $\mathrm{M}$ ) are labeled at the right.

results were obtained for chymotrypsin (data not shown). Similar to previous results for other pyruvate:quinone oxidoreductases, CidC was protected from proteolytic cleavage only if pyruvate and $\mathrm{TPP} / \mathrm{Mg}^{2+}$ were all available to the enzyme, e.g., when the enzyme was fully reduced. However, the protection is very efficient only at $\mathrm{pH} 6$ and is completely absent at $\mathrm{pH}$ 7. During the $30 \mathrm{~min}$ cleavage at $\mathrm{pH} \mathrm{6}$, only a minute fraction of CidC cleaved to a product labeled as $\mathrm{CidC}^{1}$, while at $\mathrm{pH} 7$, most of the enzyme was converted to $\mathrm{CidC}^{1}$ and $\mathrm{CidC}^{2}$. CidC ${ }^{1}$ and $\mathrm{CidC}^{2}$ are only a few kilodaltons and $\sim 20$ $\mathrm{kDa}$ smaller, respectively, than CidC and resemble the 58 and $51 \mathrm{kDa}$ species obtained by proteolysis of the E. coli PoxB previously reported. ${ }^{35}$ No further attempts were made to characterize these truncated proteins at the amino acid sequence level.

When either (i) pyruvate, (ii) TPP and $\mathrm{Mg}^{2+}$, or (iii) $\mathrm{Mg}^{2+}$ was provided to CidC, trypsin was very effective in cleaving $\mathrm{CidC}$ at $\mathrm{pH} 6$ and 7 (Figure 6). These results suggest that CidC is protected from trypsin only when it is active (at $\mathrm{pH} 6)$ and when both the pyruvate substrate and the TPP $/ \mathrm{Mg}^{2+}$ cofactors are present; in other words, the reducing form of CidC (with $\mathrm{FADH}_{2}$ and TPP) adopts a conformation that is protected from proteolysis. The activities of the $\mathrm{CidC}^{1}$ and $\mathrm{CidC}^{2}$ degradation products were also investigated using the ferricyanide assay and were found to be as active as their CidC parent at $\mathrm{pH} 6$; as with the intact enzyme, no measurable activity of the truncated proteins could be detected at $\mathrm{pH} 7$ (data not shown).

CidC Is Coupled to the Respiratory Chain via Menaquinone. E. coli pyruvate:quinone oxidoreductase, PoxB, transfers electrons directly into the electron transport chain via ubiquinone. ${ }^{47,48}$ Similarly, C. glutamicum pyruvate oxidase reduces menaquinone-9. Like other Gram-positive bacteria, $S$. aureus possesses only menaquinone, so we speculated that CidC would be able to pass electrons to menaquinone. To test this, the most soluble forms of menaquinone and ubiquinone, menadione (MN0) and CoQ0, respectively, were used as electron acceptors in this experiment. MNO and CoQ0 have the exact same headgroups compared with their counterparts and vary only in the hydrophobic chains, which function as membrane anchors. In addition, cytochrome $c$ was used as an artificial electron acceptor in this experiment, where its reduction can be monitored by following the change in $A_{550}$ over time.

As shown in Figure 7, efficient electron transfer was observed only with MNO (cytochrome $c$ was completely reduced within

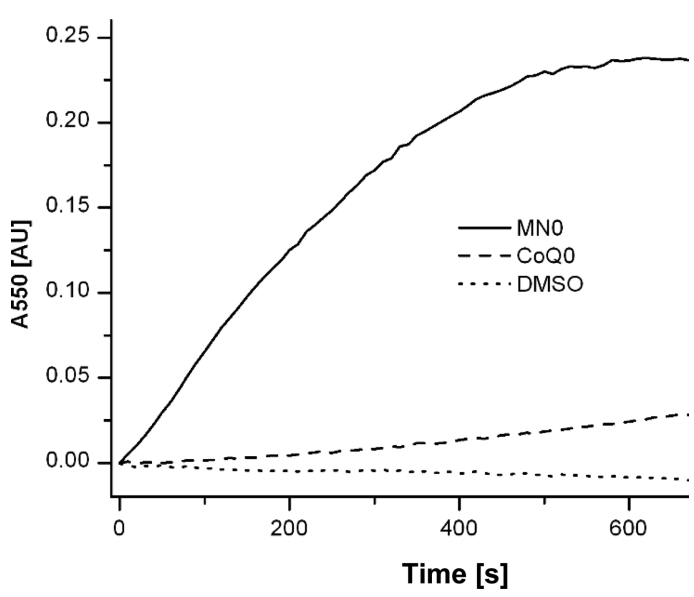

Figure 7. Quinone reduction by CidC. Electron transport by CidC to cytochrome $c$ via MNO, CoQ0, or DMSO (control) was investigated. The oxidation state of cytochrome $c$ was measured via $A_{550}$ and is plotted as the change from its oxidized state.

$10 \mathrm{~min}$ of the start of the reaction) while very little transfer was observed via CoQ0 or in the absence of any quinone. Kinetic studies demonstrated that CidC has the highest affinity (0.7 $\mathrm{mM})$ and turnover rate $\left(0.26 \mathrm{~s}^{-1}\right)$ for pyruvate at $\mathrm{pH} 5.6$ and 6.0 using $\mathrm{MNO}$ as an electron receptor. In contrast, CoQ0 has a much lower affinity $(2.54 \mathrm{mM})$ and a lower turnover rate $(0.05$ $\mathrm{s}^{-1}$ ). Compared with the results of the previous ferricyanide experiment, CidC has a much higher specificity, but a much lower turnover rate, for menadione because there are multiple electron transfer steps happening in the menadione/cytochrome $c$ assays and we are measuring only the overall turnover rate for these reactions. These results suggest that CidC can participate in the $S$. aureus respiratory chain via menaquinone.

\section{DISCUSSION}

The extensively studied PoxB pyruvate:ubiquinone oxidoreductase from E. coli directly shuffles electrons from the cytoplasm to the membrane-bound mobile carrier ubiquinone 
of the electron transport chain where it converts pyruvate to acetate. PoxB is inactive within the cytoplasm where the $\mathrm{C}$ terminus sterically hinders the active site from both the pyruvate substrate and the ubiquinone electron acceptor. $^{25,44,49,50}$ PoxB becomes active in vivo by binding to the membrane via this $\mathrm{C}$-terminal domain, which undergoes a structural rearrangement exposing the active binding site to the solvent and activating the enzyme by 2 orders of magnitude (affecting both turnover and pyruvate affinity). This behavior can be reproduced in vitro by binding to artificial phospholipid membranes and detergent micelles, or by proteolytic cleavage of the C-terminus. ${ }^{25}$ This current in vitro study reveals novel insights into the CidC protein from $S$. aureus, which differs from PoxB in some aspects. CidC is also a membrane-bound protein; however, it is only modestly activated by binding to artificial membranes or by proteolytic cleavage, which increases its activity by a factor of only $\sim 3$. This behavior may be explained by a slightly different structure of $\mathrm{CidC}$ where the $\mathrm{C}$ terminus may not inhibit access of the solvent to the active site in the membrane-free form of the protein. CidC is able to efficiently pass electrons to menaquinone, the quinone found within the $S$. aureus membranes, which lack ubiquinone, and thus could actively participate in the electron transport chain. $\mathrm{CidC}$ is active under conditions slightly more acidic than $\mathrm{pH}$ 6.5 and is largely inactive at $\mathrm{pH} 7-8$, most likely because of its inability to bind the TPP cofactor at neutral $\mathrm{pH}$. This is in contrast to POX, which retains $\sim 50$ and $\sim 20 \%$ of its activity at pH 7 and 8, respectively. ${ }^{20}$ CidC, therefore, appears to be intrinsically "activated" only when the cytoplasm becomes sufficiently acidic, at which point it could further contribute to intracellular acidification by generating acetate. Thus, these findings are consistent with our previous finding that cytoplasmic acidification is important in the induction of bacterial PCD and the role of the CidC protein in this process. $^{16}$

One of the major hurdles that we encountered in this study was the propensity of CidC to precipitate under its optimum working $\mathrm{pH}$. We employed multiple approaches to overcome this, including the use of different buffer formulations (altered buffer, salt, mild detergent, amino acids, etc.) to stabilize CidC at acidic $\mathrm{pH}$. We also tried adding TPP and pyruvate to the CidC sample to determine if these molecules effected precipitation. Given that all of these conditions failed, we hypothesize that active CidC may require some significant conformational change that exposes a highly charged domain and leads to precipitation. Also, the fact that CidC precipitates at its optimum working $\mathrm{pH}$ (by itself or with TPP, pyruvate, or membranes) might be due to the possibility that CidC has one or more binding partners (proteins) in vivo. Recent studies ${ }^{3,12}$ suggest that CidC may interact with the CidA and CidB proteins at the membrane. Thus, these results may indicate that CidC is normally present within one or more multiprotein complexes that serve to simultaneously regulate its activity and stabilize it.

Our laboratory has recently demonstrated the role of cidC and cytoplasmic acidification in bacterial cell death: stationary phase death was found to be dependent on CidC-generated acetate and, subsequently, extracellular acetic acid that, in the protonated and uncharged form, freely passes across the cytoplasmic membrane where it then dissociates and acidifies the cytoplasm. ${ }^{16}$ As in eukaryotic cells undergoing apoptosis, ${ }^{51,52}$ death in $S$. aureus under these conditions was shown to be associated with the accumulation of reactive oxygen species
(ROS), and the level of cell death decreased when the production of these reactive molecules was limited. ${ }^{16}$ It was also demonstrated that the physiological features that accompany the metabolic activation of cell death are strikingly similar to the hallmarks of eukaryotic apoptosis, including ROS generation and DNA fragmentation. Although the cidC gene is co-expressed with cidA, previously shown to be involved in the control of PCD in $S$. aureus, there is currently limited information about the potential interactions between these proteins. Recently, we demonstrated that the association of CidC with the membrane, as well as CidC-induced acetate generation, is promoted by $\mathrm{CidB}$. On the other hand, the presence of CidA inhibits the membrane localization of CidC. ${ }^{12}$ The functions of these proteins in PCD may therefore be interdependent, and current investigations in our laboratory are exploring this possibility.

Another important finding of this study was that CidC converts pyruvate to acetate and is likely to transfer electrons directly to menaquinone during this process. These results are consistent with previous studies in our laboratory ${ }^{15}$ and indicate that CidC may be more accurately described as a pyruvate:menaquinone oxidoreductase, rather than a pyruvate oxidase as was previously presumed on the basis of the close sequence alignment of these two classes of enzymes. Interestingly, pyruvate:oxygen 2-oxidoreductases have also been shown to be involved in cell death in the organisms that produce them. For example, the well-described death of Streptococcus pneumoniae in the stationary phase has been shown to be dependent on the expression of the $\operatorname{spxA}$ gene encoding a pyruvate:oxygen 2-oxidoreductase, which generates hydrogen peroxide and induces cell death. ${ }^{23}$ Thus, despite catalyzing distinct enzymatic reactions with different metabolic end products, both enzymes appear to play major roles in the induction of bacterial cell death.

In summary, the results of this study provide important new details about the CidC activity previously shown to be involved in the generation of acetate and the potentiation of PCD. This will be particularly important as we explore the possible interactions of CidC with CidA and/or CidB and will be critical as we dissect the molecular mechanisms underlying bacterial cell death.

\section{ASSOCIATED CONTENT}

\section{S Supporting Information}

The Supporting Information is available free of charge on the ACS Publications website at DOI: 10.1021/acs.biochem.7b00570.

Reaction products of and cofactors associated with the $S$. aureus pyruvate:menaquinone oxidoreductase enzyme (PDF)

\section{AUTHOR INFORMATION}

\section{Corresponding Author}

*Department of Pathology \& Microbiology, University of Nebraska Medical Center, 985900 Nebraska Medical Center, Omaha, NE 68198-5900. Telephone: 402-559-4945. E-mail: kbayles@unmc.edu.

\section{ORCID}

Kenneth W. Bayles: 0000-0001-9521-3540

\section{Author Contributions}

X.Z. performed the experiments. X.Z. and S.L. conceived the experiments. K.W.B., X.Z., and S.L. wrote the manuscript. 


\section{Funding}

This work was supported by National Institutes of Health Grants P01-AI83211 (K.W.B.) and R01-AI125589 (K.W.B.).

\section{Notes}

The authors declare no competing financial interest.

\section{ACKNOWLEDGMENTS}

We thank Dr. Luis A. Marky for help with the ITC experiments and Dr. Vinai C. Thomas for help with the acetate measurements and discussions about the manuscript.

\section{REFERENCES}

(1) Yang, S. J., Rice, K. C., Brown, R. J., Patton, T. G., Liou, L. E., Park, Y. H., and Bayles, K. W. (2005) A LysR-type regulator, CidR, is required for induction of the Staphylococcus aureus cidABC operon. J. Bacteriol. 187, 5893-5900.

(2) Rice, K. C., Nelson, J. B., Patton, T. G., Yang, S., and Bayles, K. W. (2005) Acetic acid induces expression of the Staphylococcus aureus cid $A B C$ and $\operatorname{lrg} A B$ murein hydrolase regulator operons. J. Bacteriol. $187,813-821$.

(3) Groicher, K. H., Firek, B. A., Fujimoto, D. F., and Bayles, K. W. (2000) The Staphylococcus aureus $\operatorname{lrg} \mathrm{AB}$ operon modulates murein hydrolase activity and penicillin tolerance. J. Bacteriol. 182, 17941801.

(4) Pang, X., Moussa, S. H., Targy, N. M., Bose, J. L., George, N. M., Gries, C., Lopez, H., Zhang, L., Bayles, K. W., Young, R, and Luo, X. (2011) Active Bax and Bak are functional holins. Genes Dev. 25, 22782290.

(5) Rice, K. C., Firek, B. a, Nelson, J. B., Patton, T. G., Bayles, K. W., and Yang, S. (2003) The Staphylococcus aureus cidAB Operon: Evaluation of Its Role in Regulation of Murein Hydrolase Activity and Penicillin Tolerance. J. Bacteriol. 185, 2635-2643.

(6) Mann, E. E., Rice, K. C., Boles, B. R., Endres, J. L., Ranjit, D., Chandramohan, L., Tsang, L. H., Smeltzer, M. S., Horswill, A. R., and Bayles, K. W. (2009) Modulation of eDNA release and degradation affects Staphylococcus aureus biofilm maturation. PLoS One 4, e5822.

(7) Rice, K. C., and Bayles, K. W. (2008) Molecular control of bacterial death and lysis. Microbiol. Mol. Biol. Rev. 72, 85-109.

(8) Bayles, K. W. (2014) Bacterial programmed cell death: making sense of a paradox. Nat. Rev. Microbiol. 12, 63-69.

(9) Rice, K. C., Mann, E. E., Endres, J. L., Weiss, E. C., Cassat, J. E., Smeltzer, M. S., and Bayles, K. W. (2007) The cidA murein hydrolase regulator contributes to DNA release and biofilm development in Staphylococcus aureus. Proc. Natl. Acad. Sci. U. S. A. 104, 8113-8.

(10) Wang, I. N., Smith, D. L., and Young, R. (2000) Holins: the protein clocks of bacteriophage infections. Annu. Rev. Microbiol. 54, 799-825.

(11) Ranjit, D. K., Endres, J. L., and Bayles, K. W. (2011) Staphylococcus aureus CidA and LrgA proteins exhibit holin-like properties. J. Bacteriol. 193, 2468-2476.

(12) Chaudhari, S. S., Thomas, V. C., Sadykov, M. R., Bose, J. L., Ahn, D. J., Zimmerman, M. C., and Bayles, K. W. (2016) The LysRtype transcriptional regulator, CidR, regulates stationary phase cell death in Staphylococcus aureus. Mol. Microbiol. 101, 942-953.

(13) Beltrame, C. O., Côrtes, M. F., Bonelli, R. R., Côrrea, A. B. d. A., Botelho, A. M. N., Américo, M. A., Fracalanzza, S. E. L., and Figueiredo, A. M. S. (2015) Inactivation of the Autolysis-Related Genes $\operatorname{lrgB}$ and yycI in Staphylococcus aureus Increases Cell LysisDependent eDNA Release and Enhances Biofilm Development In Vitro and In Vivo. PLoS One 10, e0138924.

(14) Wang, J., and Bayles, K. W. (2013) Programmed cell death in plants: Lessons from bacteria? Trends Plant Sci. 18, 133-139.

(15) Patton, T. G., Rice, K. C., Foster, M. K., and Bayles, K. W. (2005) The Staphylococcus aureus cidC gene encodes a pyruvate oxidase that affects acetate metabolism and cell death in stationary phase. Mol. Microbiol. 56, 1664-1674.
(16) Thomas, V. C., Sadykov, M. R., Chaudhari, S. S., Jones, J., Endres, J. L., Widhelm, T. J., Ahn, J.-S., Jawa, R. S., Zimmerman, M. C., and Bayles, K. W. (2014) A central role for carbon-overflow pathways in the modulation of bacterial cell death. PLoS Pathog. 10, e1004205.

(17) Knappe, J., Blaschkowski, H. P., Grobner, P., and Schmitt, T. (1974) Pyruvate Formate-Lyase of Escherichia coli: the AcetylEnzyme Intermediate. Eur. J. Biochem. 50, 253-263.

(18) Arjunan, P., Nemeria, N., Brunskill, A., Chandrasekhar, K., Sax, M., Yan, Y., Jordan, F., Guest, J. R., and Furey, W. (2002) Structure of the pyruvate dehydrogenase multienzyme complex E1 component from Escherichia coli at 1.85 A resolution. Biochemistry 41, 52135221.

(19) Abdel-Hamid, a M., Attwood, M. M., and Guest, J. R. (2001) Pyruvate oxidase contributes to the aerobic growth efficiency of Escherichia coli. Microbiology 147, 1483-1498.

(20) Sedewitz, B., Schleifer, K. H., and Gotz, F. (1984) Purification and Biochemical Characterization of Pyruvate Oxidase from Lactobacillus plantarum. J. Bacteriol. 160, 273-278.

(21) Schreiner, M. E., and Eikmanns, B. J. (2005) Pyruvate:quinone oxidoreductase from Corynebacterium glutamicum: purification and biochemical characterization. J. Bacteriol. 187, 862-871.

(22) Wolfe, A. J. (2005) The acetate switch. Microbiol. Mol. Biol. Rev. $69,12-50$.

(23) Regev-Yochay, G., Trzcinski, K., Thompson, C. M., Lipsitch, M., and Malley, R. (2007) SpxB is a suicide gene of Streptococcus pneumoniae and confers a selective advantage in an in vivo competitive colonization model. J. Bacteriol. 189, 6532-6539.

(24) Goffin, P., Muscariello, L., Lorquet, F., Stukkens, A., Prozzi, D., Sacco, M., Kleerebezem, M., and Hols, P. (2006) Involvement of pyruvate oxidase activity and acetate production in the survival of Lactobacillus plantarum during the stationary phase of aerobic growth. Appl. Environ. Microbiol. 72, 7933-7940.

(25) Neumann, P., Weidner, A., Pech, A., Stubbs, M. T., and Tittmann, K. (2008) Structural basis for membrane binding and catalytic activation of the peripheral membrane enzyme pyruvate oxidase from Escherichia coli. Proc. Natl. Acad. Sci. U. S. A. 105, 17390-17395.

(26) Muller, Y. a, Schumacher, G., Rudolph, R., and Schulz, G. E. (1994) The refined structures of a stabilized mutant and of wild-type pyruvate oxidase from Lactobacillus plantarum. J. Mol. Biol. 237, 315335.

(27) Chaudhari, S. S., Thomas, V. C., Sadykov, M. R., Bose, J. L., Ahn, D. J., Zimmerman, M. C., and Bayles, K. W. (2016) The LysRtype transcriptional regulator, CidR, regulates stationary phase cell death in Staphylococcus aureus. Mol. Microbiol. 101, 942-953.

(28) Tittmann, K., Golbik, R., Ghisla, S., and Hübner, G. (2000) Mechanism of elementary catalytic steps of pyruvate oxidase from Lactobacillus plantarum. Biochemistry 39, 10747-54.

(29) Trinder, P. (1969) Determination of blood glucose using an oxidase-peroxidase system with a non-carcinogenic chromogen. J. Clin. Pathol. 22, 158-161.

(30) Brocklehurst, K., and Dixon, H. B. (1976) PH-dependence of the steady-state rate of a two-step enzymic reaction. Biochem. J. 155, 61-70.

(31) Risse, B., Stempfer, G., Rudolph, R., Möllering, H., and Jaenicke, R. (1992) Stability and reconstitution of pyruvate oxidase from Lactobacillus plantarum: dissection of the stabilizing effects of coenzyme binding and subunit interaction. Protein Sci. 1, 1699-1709.

(32) Chang, Y. Y., and Cronan, J. E. (1984) An Escherichia coli mutant deficient in pyruvate oxidase activity due to altered phospholipid activation of the enzyme. Proc. Natl. Acad. Sci. U. S. A. $81,4348-4352$.

(33) Mather, M., Blake, R., Koland, J., Schrock, H., Russell, P., O’Brien, T., Hager, L. P., Gennis, R. B., and O'Leary, M. (1982) Escherichia coli pyruvate oxidase: interaction of a peripheral membrane protein with lipids. Biophys. J. 37, 87-88.

(34) Schrock, H. L., and Gennis, R. B. (1977) High affinity lipid binding sites on the peripheral membrane enzyme pyruvate oxidase. 
Specific ligand effects on detergent binding. J. Biol. Chem. 252, 59905995.

(35) Russell, P., Schrock, H. L., and Gennis, R. B. (1977) Lipid activation and protease activation of pyruvate oxidase. Evidence suggesting a common site of interaction on the protein. J. Biol. Chem. 252, 7883-7887.

(36) Short, S. a., and White, D. C. (1971) Metabolism of phosphatidylglycerol, lysylphosphatidylglycerol, and cardiolipin of Staphylococcus aureus. J. Bacteriol. 108, 219-226.

(37) Kilelee, E., Pokorny, A., Yeaman, M. R., and Bayer, A. S. (2010) Lysyl-phosphatidylglycerol attenuates membrane perturbation rather than surface association of the cationic antimicrobial peptide $6 \mathrm{~W}-\mathrm{RP}-1$ in a model membrane system: implications for daptomycin resistance. Antimicrob. Agents Chemother. 54, 4476-4479.

(38) Blake, R., and Hager, L. P. (1978) Activation of pyruvate oxidase by monomeric and micellar amphiphiles. J. Biol. Chem. 253, 19631971.

(39) Grabau, C., and Cronan, J. E. (1984) Molecular cloning of the gene (poxB) encoding the pyruvate oxidase of Escherichia coli, a lipidactivated enzyme. J. Bacteriol. 160, 1088-1092.

(40) Grabau, C., and Cronan, J. E. (1986) In vivo function of Escherichia coli pyruvate oxidase specifically requires a functional lipid binding site. Biochemistry 25, 3748-3751.

(41) Morey, A. V., and Juni, E. (1968) Studies on the nature of the binding of thiamine pyrophosphate to enzymes. J. Biol. Chem. 243, 3009-3019.

(42) Kulshina, N., Edwards, T. E., and Ferré-D’Amaré, A. R. (2010) Thermodynamic analysis of ligand binding and ligand binding-induced tertiary structure formation by the thiamine pyrophosphate riboswitch. RNA 16, 186-196.

(43) Muller, Y. A., and Schulz, G. E. (1993) Structure of the thiamine- and flavin-dependent enzyme pyruvate oxidase. Science 259, 965-967.

(44) Recny, M. A., and Hager, L. P. (1983) Isolation and characterization of the protease-activated form of pyruvate oxidase. Evidence for a conformational change in the environment of the flavin prosthetic group. J. Biol. Chem. 258, 5189-5195.

(45) Recny, M. A., Grabau, C., Cronan, J. E., and Hager, L. P. (1985) Characterization of the $\alpha$-peptide released upon protease activation of pyruvate oxidase. J. Biol. Chem. 260, 14287-14291.

(46) Russell, P., Hager, L. P., and Gennis, R. B. (1977) Characterization of the proteolytic activation of pyruvate oxidase. Control by specific ligands and by the flavin oxidation-reduction state. J. Biol. Chem. 252, 7877-7882.

(47) Carter, K., and Gennis, R. B. (1985) Reconstitution of the ubiquinone-dependent pyruvate oxidase system of Escherichia coli with the cytochrome o terminal oxidase complex. J. Biol. Chem. 260, 10986-10990.

(48) Koland, J. G., Miller, M. J., and Gennis, R. B. (1984) Reconstitution of the membrane-bound, ubiquinone-dependent pyruvate oxidase respiratory chain of Escherichia coli with the cytochrome d terminal oxidase. Biochemistry 23, 445-453.

(49) Cunningham, C. C., and Hager, L. P. (1975) Reactivation of the lipid-depleted pyruvate oxidase system from Escherichia coli with cell envelope neutral lipids. J. Biol. Chem. 250, 7139-7146.

(50) Mather, M. W., and Gennis, R. B. (1985) Spectroscopic studies of pyruvate oxidase flavoprotein from Escherichia coli trapped in the lipid-activated form by cross-linking. J. Biol. Chem. 260, 10395-10397.

(51) Simon, H. U., Haj-Yehia, A., and Levi-Schaffer, F. (2000) Role of reactive oxygen species (ROS) in apoptosis induction. Apoptosis 5, $415-418$.

(52) Granot, D., Levine, A., and Dor-Hefetz, E. (2003) Sugarinduced apoptosis in yeast cells. FEMS Yeast Res. 4, 7-13. 